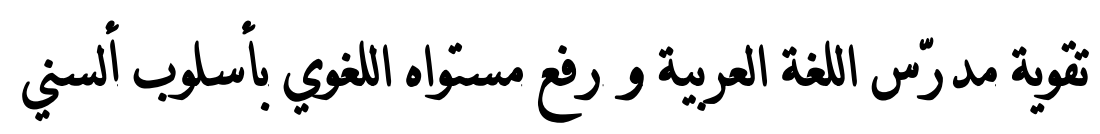

\author{
Majidatun Ahmala \\ Sekolah Tinggi Agama Islam (STAI) Taruna Surabaya \\ Mazida23@gmail.com
}

\begin{abstract}
Arabic in Indonesia is not only the language of religion, inheritance and civilization but also the language of communication between Arabic instructors or between Arabic students. In addition, Arabic is also daily language used in boarding schools that are scattered throught the regions in Indonesia. Arabic always develops according to the times. So, all Arabic instructors must also improve their competence. Madrasah Al-Sun education institutions seemed to be a solution for all Arabic language teachers in Indonesia, because the Madrasah Al-Sun used a special strategy in its teaching, namely Uslub Al-Sun. By using Uslub Al-Sun, the instructor is able to learn more deeply about Islamic civilization and is able to master contemporary vocabulary due to active discussions conducted. This study uses qualitative methods so that researchers get more in-depth data in accordance with the facts in the foeld about Uslub Al-Sun that is used to improve the teaching competence of Arabic.
\end{abstract}

Keywords: Arabic Language, Arabic Language Teacher, Al-Sun Uslub, teacher competence, Arabic language development.

\begin{abstract}
ABSTRAK: Bahasa Arab di Indonesia bukan hanya bahasa agama, warisan dan peradaban saja tetapi juga bahasa komunikasi antar pengajar bahasa Arab atau antar pelajar bahasa Arab. Selain itu, bahasa Arab juga menjadi bahasa sehari-hari yang digunakan di pesantren-pesantren yang tersebar di seluruh penjuru daerah di Indonesia. Bahasa Arab senantiasa berkembang sesuai dengan perkembangan zaman. Maka, segenap pengajar bahasa Arab pun harus meningkatkan kompetensi mereka. Lembaga pendidikan Madrasah Al-Sun seakan menjadi solusi bagi segenap pengajar bahasa Arab di Indonesia, karena Madrasah Al-sun menggunakan strategi khusus dalam pengajarannya, yaitu uslub Al-Sun. Dengan menggunakan Uslub Al-Sun ini pengajar mampu mempelajari lebih mendalam tentang peradaban Islam dan mampu menguasai kosakata kontemporer disebabkan adanya diskusi aktif yang dilakukan. Penelitian ini menggunakan metode kualitatif agar peneliti mendapatkan data lebih mendalam sesuai dengan fakta-fakta yang ada di lapangan tentang Uslub Al-Sun yang digunakan untuk meningkatkan kompetensi pengajar bahasa Arab.
\end{abstract}

Kata Kunci: Bahasa Arab, Pengajar bahasa Arab, Uslub Al-Sun, kompetensi guru, perkembangan bahasa Arab 
إن اللغة ليست أداة عقلية خفسب بل في اللغة عنصر إنعالي وعاطفي فالإنسان ينكم ليؤثر في غيره وليعبر عن شعوره وعواطفه كما يعبر عن آرائه. فهذه هي وظيفة اللغة وهي وسيلة الإنسان لكشف ما خطر على باله وعواطفه حتى وصلت إلى غاية اللغة وهي التواصل والثفاعل بين الناس.

الاتصال هو العملية التي يتم عن طريقها انتقال المعرفة من شخص لآخر حتى تصبح مشاعة بينها، وتؤدي

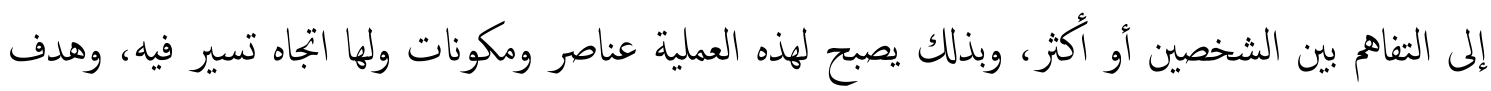
تسعى إلى تحقيقه، ومجال تعمل فيه، ويؤثر فيها مما يخضعها للملاحظة، والبحث، والتجريب والدراسة العملية بوجه c

والتواصل اللغوى أساس كل تقدم إنسانى، وهو صفة أساسية لأى تجمع بشرى. فالإنسان يجب عليه أن يشارك جاره في خبرته وأفكاره، وهو أبضاً يجب أن يكون لديه شيئ ما يشترك به مع هذا الجار ، وهو أخيراً يجب أن يتصل به، وضعف الاتصال أو تخلفه يقف وراء معظم النرور والكوارث التى يعانى منها العالم، فعدم القدرة على ما في عقل الجار ، وغياب الأساس المشترك للفهم هو السبب في الصراع معه بدلاً من الفهم المتبادل. ${ }^{3}$ واللغة في هذه الأنشطة هي أداة التواصل لنقل المعارف من شخص لشخص آخر.

قال مصطفى حركات، أهم الوظائف من اللغة هي وظيفة التواصل لأن اللغة تعتبر أساسا كأداة لنقل المعلومات. ${ }^{4}$ وتبادل المعانى عند عملية الاتصال باستخدام اللغة التي تعتبر أداة للتعبير عما في نقوسهم ولإفهام غيرهم عا يريدون.

اللغة العربية ليست لغة غريبة من الجمتمعات الإسلامية غير العرب، حيث إندونيسيا تمثل أغلبية ساحقة وأكبر المسلمين في العالم. رغز أن سكانهم يتحدثون باللغة الإندونيسية ولكن اللغة العربية تشبه لغتهم اليومية لأن هذه اللغة هي لغة عقيدته.

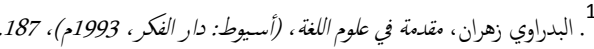

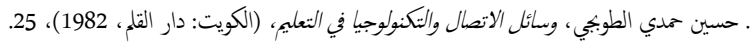

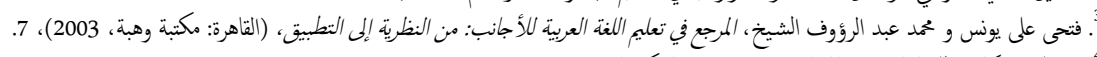

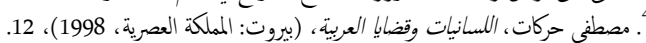


إن بين اللغة العربية والعقيدة الإسلامية ترابطا عضويا وثيقا لايماثله ترابط آخر في أي مجتمع من المجتمات الأخري القديمة والمعاصرة، فإها لغة الإسلام والمسلمين في جميع بقاع الدنيا، ولغة كتابه المبين، بها يؤدي المسلمون صلاتهم، ويتلون كتاب ربهم، وأحاديث نبيه، ويلبون في ججهم، ويتضرعون في دعائه. 5

في العصور الحديثة تهيأت للغة العربية عوامل جديدة للتطور والتقدم، فقد ارتفعت الصحافة، وانتشر

التعليم. وأنشع مجع اللغة العربية، وهى الآن اللغة الرسمية في جميع الأقطار العربية الشقيقة. ولغة التفاهم بين جميع الشعوب العربية. كما أنها لغة التعليم في جميع المدارس والمعاهد وأكثر الكليات الجامعية. وهى كذلك لغة الصحافة، والإذاعة، والقضاء، والتأليف في البلاد العربية. إذن، اللغة العربية هي الوعاء الذي يجمع تراث العرب الفكري والحضاري.7

عملية التعليم هى عملية اتصال يحاول المعلم عن طريقها إكساب الدارسين المهارات والخبرات المطلوبة، ويستخدم لذلك وسائل تعينه على ذلك، مع جعل المتعلم مشاركا لما يدور حوله في قاعة الدرس. ${ }^{8}$ فلذلك، استخدم المدرسون اللغة العربية أسالب متنوعة وجذابة لإكتساب اللغة العربية لدي الدارسين بشكل تطبيقي وتفاعلي.

الأساليب هي الخطط والتدبير والخطوات والوسائل التي تأخذ مكانها فعلا في حجرة الدراسة وتستخدم

لتحقيق الهدف من عملية التدريس في الموقف التعليمي ذاته، ويجب أن ترتبط هذه الخطط والتدابير والخطوات ارتباطا قويا بالإطار العام للطريقة، وبالنالي يجب أن يكون بينها وبين المدخل الأساسي انسجام واتساق كامل.9 اللغة تمر بمرور الزمان، ولابد لمدرس اللغة العربية أن يعلم اللفة العربية حسب تقدم الزمان، كما في الاعتبار " علموا أولادك حسب زمانه". ولذالك وجب على مدرس اللغة العربية ترقية وتحديث لغته العربية حسب تقدم زمان طلابه لتوفير التعليم جو التشويق والمتعة لأن الطلبة خلقوا في زمانهم و المدرسون يعلمون حسب زمانهم أيضاً.

5. 5 يعقوب بكر ، العربية لغة عالمية، (القاهرة: جامعة الدول العربية، 1966)، 16.

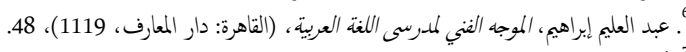

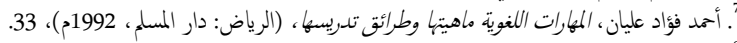

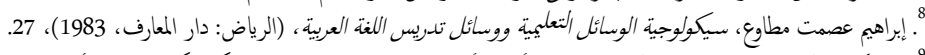

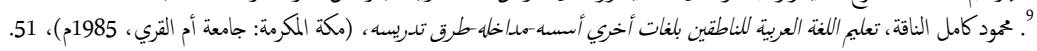


إلى جانب ذلك، تشير الدراسات إلى أن التفكير بلغة أخرى لا يستلزم فقط تطوير الكفاءة العالية في

اللغة ولكن الأهم هو إعادة هيكة المفاهيم وإعادة تفسير الواقع من خلال المفاهيم والمنظورات اللغوية الجديدة. 10 ووجب على مدرس اللغة العربية بلغة أخرى إعادة هيكلة المفاهيم وإعادة تفسير الواقع من من خلال المفاهيم والمنظورات اللغوية الجديدة بشكل مستمر في كل عصر.

ومن بعض الأمثلة على تقدم الزمان في تعليم اللغة العربية هي: تعليم اللغة العربية بالطريقة الحديثة، وإستخدام الوسائل التعليمية التكنولوجية، والمفردات المعاصرة المستخدمة في المجتمع، وتقدم الحضارة الاسلامية، وغير ذلك.

يعتبر التعلم تحما للطلاب وإنجازاتهم التعليمية، التعلم محم أيضا للمعلمين لأن التعلم للمعلمين يعزز تفكيرهم وإدراكهم وعملهم ويفتح أبعادا جديدة لفهم المواد الدراسية، والحالات، والقضايا، والمشاكل المتعلقة بالنظام والإنسان والمجتمع. 11 لذلك، يجب على المعلمين تحسين قدرته العربية عن طريق التعلم على الأشياء الجديدة في تعليم اللغة العربية.

ولكن كثيرا من مدرسي اللغة العربية لم يجدوا مكانا ليتعلموا وليناقثوا ذلك كله. فضضور مدرسة الألسن في

سيدوآرجو جاوى الثرقية إندونسيا تكون حلا لتلك المشكلة، لأن مدرسة الألسن هي إحدي المؤسسات التربوية التي تعمل في حقل تعليم اللغة العربية بشكل غير رسمي. هذا المكان يكون منتدى للتواصل بين مدرسي اللغة العربية من أنحاء المنطقة في إندونيسيا.

هذه المدرسة تستخدم أسلوبا خاصا وهو "أسلوب ألسني." هذا الأسلوب يقدر المدرس أن يتعرف بعمق على مجال في الحضارة الإسلامية بدرس تفسير القرآن أو الحديث، ويطورنفسه في مجال تعليم اللغة العربية

${ }^{10}$. Maria C. M. de Guerrero, Going Covert: Inner and Private Speech in Language Learning. State-of-theArt Article: Lang. Teach. 2018, 51.1, Cambridge University Press 2017, doi: 10.1017/S0261444817000295, 18. Downloaded from https://www.cambridge.org/core. IP address: 120. 188.80.81, on 08 Feb 2019. 11 . Zafarullah Sahito dan Joensuu Finland, Quality in Teacher Education: Evidence from the Universities of Sindh, Pakistan. Journal of Language Teaching and Research, Vol. 9, No. 5, pp. 916-927, Sepetember 2018, 5. 
في إندونيسيا بدرس طريقة تعليم اللغة العربية للناطقين بغيرها، ويسيطر المدرس على المفردات المعاصرة المستخدمة حسب تقدم الزمان.

فلذلك، أخذت الباحثة موضوع بثها تحت العنوان " تقوية مدرس اللغة العربية ورفع مستواه اللغوي بأسلوب ألسونى"، لأن الباحثة تريد أن تعرف كيفة استخدام هذا الأسلوب حتى يقدر على سيطرة مدرس اللغة العربية حسب تقدم الزمان.

\section{مشكة البحث}

اسنادا إلى ما في المقدمة من البيانات، فالمشكلة التى تريد الباحثة حلها وعلانجا في بكثا وهى: (1)كف وظيفة المعلم، والمتعلم، والمتوى في أسلوب ألسونى؟. ب) كيف خطوات تدريس أسلوب ألسونى؟. ؟) ما مدى فعالية استخدام أسلوب ألسونى لمدرس اللغة العربية؟ أهداف البحث نظرا إلى مشكلة البحث الموجودة فنكون أهداف هذا البحث هى: ( ) لمعرفة وظيفة المعلم، والمتعلم، والمتوى في أسلوب ألسونى. Y) لمعرفة خطوات تدريس أسلوب ألسونى. r) لمعرفة ما مدى فعالية استخدام أسلوب ألسونى لمدرس اللغة العربية؟ - م

\section{مناج البحث}

استخدمت الباحثة المدخل الكيفي لوصف وتحليل الظواهر، والحوادث، والأنشطة الإجتاعية، والمواقف، والثقة، والإدراك، وتفكير الإنسان بشكل فردي أو مجموعات. 12 بهذا المدخل تقدر الباحثة أن تتعرف بعمق على الأنشطة التعليمية المستخدمة في مدرسة الألسن حتى تتعرف الباحثة بعمق عن الأسلوب الألسنى. ونوع هذا البحث هو منهج البحث الوصفي (Descriptive Method) وهو أسلوب من أساليب التحليل المركز على معلومات كافية وحقيقة عن ظاهرة أو موضوع محدد، أو فترة أو فترات زمنية معلومة، وذلك

12 . Nana Syaodih Sukmadinata, Metode Penelitian Pendidikan, (Bandung: Remaja Rosdakarya, 2012 ), 60. 
من أجل الحصول على نتأُ علمية، ثم تفسيرها بطريقة موضوعية، بما ينسجم مع المعطيات الفعلية للظاهرة. 13 فلذلك، وصفت الباحثة مدي فعالية استخدام أسلوب ألسنى بالتفصيل. أما مصادر البيانات في هذا البحث فهي مؤسس مدرسة ألسن، ومدارس اللغة العربية، والخطط النعليمية، والمواد الدراسية. وأما طريقة جمع البيانات المستخدمة هي (1) الملاحظة المشاركة وهي يكون للباحث دور ايجابي وفعال في احداث الملاحظة بمعنى ان الباحث يقوم بالدور نفسه ويشارك افراد الدراسة في سلوكهم والممارسة المراد دراستها. 14 وفي هذا البحث تشترك الباحثة خلال دراسة اللغة العربية التى تستخدم أسلوبا ألسنيا. (2) المقابلة تعتبر كوسيلة جمع البيانات عن طريق طرح الأسئلة والأجوبة من جانب واحد بشكل منهجي على أساس أغراض البحث. 15 قامت الباحثة بإجراء المقابلة مع مؤسس مدرسة ألسن ومدارس اللغة العربية في الصف. (3) الوثائق هي طريقة بحث البيانات فيا يتعل بالمسائل أو المتتتغيرات في شكل الملاحظات، والنصوص، والكنب، والصحف، والمجلات، والنقوش، ومضبطة مجلس، وجداول الأعال، وغيرها. 16 قامت الباحثة بالبحث المعلومات عن أساليب تعليم اللغة العربية من الكنب المستخدمة في مدرسة ألسن والكنب في المكتبة حول تعليم اللغة العربية للناطقين بغيرها. عملية تحليل البيانات تقوم عن طريق تنقيص البيانات (Reduksi data) وهى عن كيفية صياغة نظرية في مجموعة من المفاهيم التى لها مستويات عالية من التجريد على أساس تنوع مجموعة من النظريات والمناطق. 17 في هذا البحث اختارت الباحثة البيانات الضرورية للبحث وإزالة البيانات غير غير الضرورية، ثم تقديمها من خلال الانتباه بين النظرية والبيانات الموجودة في موقع البحث. نتائُ البحث أولا: مدرسة ألسن

13. رجاءو وحيد دويدري، البحث العلمي: أساسياته النظرية وممارسته العملية، (دمش: دار الفكر، 2008)، 183.

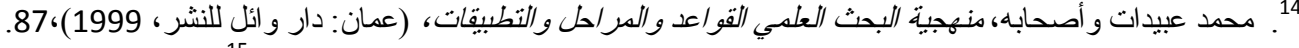

${ }^{15}$. Sutrisno Hadi, Metodologi Riset, (Yogyakarta: Pustaka Pelajar, 2016), 264. ${ }^{16}$. Suharsimi Arikunto, Posedur Penelitian: Suatu Pendekatan Praktik, (Jakarta: Asdi Mahasatya, 2006),

17 . Lexy J. Moleong, Metodologi Penelitian Kualitatif, (Bandung: Remaja Rosdakarya, 2004), 212. 
ظهور مدرسة الألسن في سيدوأرجو كؤسسة تربوية تعمل في حقل تعليم اللغة العربية بشكل غير رسمي تكون علاجا لمدرس اللغة العربية، لأن يصعب على المدرس في إيجاد المجتمع الناطق بالعربية في المنطقة المحيطة بسورابايا.

الرائد الأول وصاحب الفضل في غرس هذه البذرة هو الشيخ عبد الرحمن الذي قد أبجد نفسه وكزس جهوده وخضص جل وقته ليل نهار للتعليم والإشراف على هذه الأنشطة التعليمية في المصلى المتواضع حيث تخرج من يديه عدد من الدعاة والأساتذة والمعلمين يعملون في حقل الدعوة والتعليم وفي شتى الجمالات في سبيل توعية المسلمين ورفعة شأنهم. وكان هذا التعليم مجانا بلا أي مقابلا أي مقابل بل كانت اللوازم التعليمية تُوزَّعُ على الدارسن بالمجان أيضا. وكانت الدراسة تجرى على المستويات: مستوى تعليم ألفيات القراءة وتهجياتها ومستوى تعليم التجويد ومستوى تعليم القواعد اللغوية من النحو والصرف. وظل هذا النمط التقليدي من النعليم التجديد في مجال تعليم اللغة العربية في هذا الملكان. وقد تأسست مدرسة الألسن بعون الله تعالى بتاريخ 3 مارس 1989 م عقب عودة محد ناصر عبد الرحمن بالذات من التعليم الجامعي بجامعة الملك سعود بالرياض حيث طلب منه كثير من الراغبين في تعلم اللغة العربية تأسيس مدرسة خاصة لتعلم اللغة العربية بطريقة حديثة وفقا لبحوث متطورة في المجال التعليمي والتربوي وفقا لأنج الطرق والأساليب في مجال تعليم اللغة العربية لغير أهلها. وقد أطلقت المدرسة على نفسها اسم مدرسة الألسن تبركا وتيمّنا برسالة مدرسة الألسن بعصر ومهمها التى أسسها الشيخ رفاعة الطهطاوي والتي لها فضل كير ودور بارز في الصحوة العلمية والثقافة واللغوية بصر بل في العالم العربي بأمكله. 18 والآن، التعليم هناك يتكون من المستويات الثلاثة، المستوى الأساسي، والمستوى المتوسط والمستوى المتقدم. أغلبية دارسي المستوي المتقدم هم من المدرسين أو المدرسات في اللغة العربية في أنحاء المدارس المختلفة. فلذلك هذا المستوى يقال بمستوى المعلمين. استخدم الأستاذ محد ناصر عبد الرمن(مؤسس مدرسة الألسن) أسلوبا خاصا في تعلمه وهو أسلوب ألسني. هذا الأسلوب مستخدم في تعلمه من المستوى المبتدى حتى مستوي المعلمين. وهذا البحث ستبحث عن استخدام الأسلوب ألسني في المستوى المعلمين فقط دون الآخر.

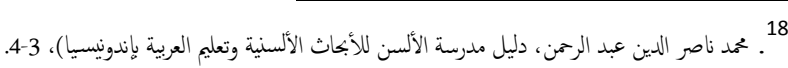


Majidatun Ahmala

تقوبة مدرّس اللغة العربة و رفع مستواه اللغوي أَسلوب أسني

ثانبا: أسلوب ألسني

هناك عدة اساليب في تعليم اللغة العربية، ولكن تلك الأساليب الكثيرة لمتعلم اللغة العربية في المدرسة، ولم يوجد أسلوب خاص لمعلم اللغة العربية بينما يحتاج المعلمون اللغة العربية في ترقية وتحديث لغتهم العربية حسب تقدم الزمان.

أسلوب ألسني هو أحد أساليب تعليم اللغة التى تغرس روح المعلم حب الاستطلاع على النصوص المكتوبة بالمناقشة الفعالة بعد شرح المدرس عن المواد التعلمية، وسوف يقومون بترقية لغته العربية وتحديثها حسب تقدم الزمان.

طريقة اكتساب اللغة وفقاً لأسلوب ألسني هي تمر بثلاث مراحل، المرحلة الأولى هى مرحلة التعرف، ومرحلة الاستيعاب، ومرحلة الاستمتاع.

في المرحلة الأولى وهي مرحلة التعرف، يقوم المدرس بشرح النصوص ثم يوضحه بالمعنى، مثلا في الترادف

نحو قوي وهو متين، أو بالثضاد نحو إيجابي (positif) ضد سلبي (negatif)، أو بمرادف المفردات وتثصاحب في الاستعال نحو لا يستغنى عن (يحتاج) و يستغنى (لايجتاج)، أو في تشابه الكلمات نحو وَعْدُ (janji) وعيد (ancaman) طريقة شرح المفردات المستخدمة لاكتساب اللغة العربية في مرحلة التعرف.

يثرح المدرس معنى المفردات بالمعنى الآخر من اللغة العربية لأن اللغة المستخدمة في حجرة الدراسة كلها اللغة العربية الفصحي الحديثة مستندة إلى كتاب التراث الاسلامي خاصة القرآن الكريم والأحاديث النبوية الثريفة. 
في المرحلة الثانية هي مرحلة الاستيعاب. مرحلة الاستيعاب هي مرحلة فهم النص في إطار الثقافة والإثارات التاريخية والجغرافية والفلكورية، والخلقية والدينية، والأطرح العامة لموقف الجمتمع صاحب اللغة من أوضاع العالم المجيط به رؤيته لهذا العالم. 19 على سبيل المثال، في بداية مادة "تعلم المهارات اللغوية" من كتاب "تعلم المهارات الحية وتعلمها بين النظرية والتطبيق" تأليف الأستاذ الدكتور عبد المجيد العربي، شرح المعلم تاريخ أسس المهارات الأربع من مذهب سلوكيين وعرفانين، (شرح هذا التاريخ غير موجود في الكناب)، ثم استمر المعلم في شرحه إلى مادة "تعلم المهارات اللغوية" الموجودة في الكتاب. وغاية شرح هذا التاريخ لفهم المتعلم عن سبب تقسيم المهارات إلى المهارات الاستيعابية والابتكارية الموجودة في الكتاب.

وفقاً لأسلوب ألسني، يستوعب المتعلم فهم معنى المفردة من جانها المعجمي، إذن فهم المتعلم المعنى الكلي للنص ليس مجرد فهم النعرف من النواحي الصوتية والصرفية والنحوية وغير ذلك. ويدل على ذلك، أن المتعلم في هذا الفصل قادرون على حسن المشاركة في الدرس، وحسن الإجابة في المناقشة، والمناقشة التي تدور بين الطلاب في الفصل تدل على الفهم، ومداومة انتباههم عند الدرس، وفهم المحتوى الثقافي للنص.

وفي مرحلة الاستتناع، يقدر المتعلم للاستمتاع بالنصوص والأسلوب الأدبي، لأن النصوص قد تؤثر في نقوسهم وعواطفهم العميقة. ويدل على ذلك أن المتعلم يقدر على أن يعبر عن مضمون النصوص بالإبداع والوضوح، كأن النصوص تقودهم إلى التأثير الجمالي.

ومثال على ذلك، في مادة "الفرق بين الرواية والدراية"، كتب فيه حديث رائع "يا معشر الفقهاء، أتخ

الأطباء، ونخن الصيادلة". من هذه العبارة يتمتع بها المتعلمون في كثف معناها.كل متعلم يعبر عما خطر في باله عن تلك الجملة، بعضهم يقول أن المعنى من تلك الجملة هي أن الفقيه كالطبيب الذي يشخص الداء ويصف له الدواء والمحدث كالصيدلية الذي توجد فيه آلاف من الأدوية، وبعض الآخر من المتعلم يزيد أن الصيدلية لا

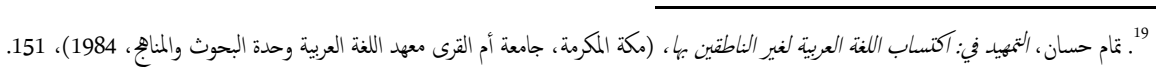


تستطع أن تصف المرضى كالمدث الذي لا يستطع أن يستنبط الأحكام من الحديث الذي حفظه.

\section{ثالثا: وظائف المعلم}

إن المعلم من أكبر العوامل على تشييد البناء القوي، والمعلم لايقل أهمية، من هذا القبيل، عن رجل

السياسة والاقتصاد. والمعلم من أولى واجباته أن يعمل على خلق عالم جديد فيه جميع منابع الخير. 20

والمعلم وفقاً لهذا الأسلوب هو المدرس الذي يدرس معلمي اللغة العربية. ووظائفه، أولا: يشرح المواد

المقررة باللغة العربية, ثانيا: يطور معنى المفردات الموجودة في المواد بالمفردات المعاصرة المستخدمة في المجتع، ثالثا: يشرح سبب ظهور النظرية، رغز أن ذلك السبب لم يذك في المواد، رابعا: يقرر أحد طلابه ليكون متحدثا في المناقشة، خامسا: يستع إلى ماقشة طلابه ويساعدهم في حل مشكلته، سادسا: يدفع طلابه ليعبروا عن رأهم وأفكارهم عن النصوص بدون خوف عن الخطأ، سابعا: أحيانا ، يصلح الأخطاء اللغوية لدي الطلاب، ولا يصلح المدرس أخطاء طلابه دائماً لينموا شجاعة طلابه في ابتكار الرأي والفكرة.

رابعا: وظائف المتعلم

أهم الدوافع التى تخرك المتعلم لتعلم اللغة العربية هي الدوافع الدينية، والدوافع التعلمية، ودوافع العمل، والدوافع السياسية، والدوافع الاقتصادية والتجارية، والدوافع الدبلوماسية، والدوافع القومية والدينية، والدوافع العلمية، والدوافع السياحية. 21أهم دوافع المتعلم اللغة العربية وفقاً في هذا الأسلوب هو الدوافع الدينية، والدوافع التعلمية، والدوافع العلمية.

إن المتعلمين وفقاً لهذا الأسلوب هم مدرسو اللغة العربية الذين قد أجادوا اللغة العربية ـ ومن وظائف المعلم هبذا الأسلوب هو، أولا: يسمع شرح المعلم ويركز اهتمهه على النصوص كأه يقرأ بالصمت، ثانيا: يسأل المعلم الكلمات الصعبة التي وجدها في النصوص لأن المعلم يشرحا باللغة العربية، ثالثا: يكنب المفردات المعاصرة الجديدة

20 . جودت الركاب، طرق تدريس اللغة العببية، (دمشق: دار الفكر ، 1988)، 51.

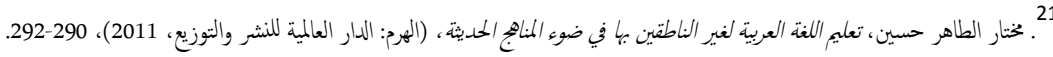


التى شرحما المعلم، رابعا: يستعد بنفسه ليكون متحدثا عندما أمره المعلم ، خامسا: يشترك في المناقشة بنشاط وهي بطرح الأسئلة إلى المتحدث، سادسا: تطوير النصوص بالمشكلة التي يوابهها المدرس في يومه، سابعا: يطرح رأيه في حل مشكلة غير هم، ثامنا: يستخدم اللغة العربية عند المناقشة أو طرح الأسئلة.

\section{خامسا: وظيفة المواد}

أن تكون مادة التعلم المقدمة للدارس مناسبة لمستواه العقلي والثقافي، وأن تكون منوعة في موضوعاتها بحيث تثير فيه رغبة للعمل وحبا للقراهة والتعلم، وبالتالي تنمي ذخيرته اللغوية لفظا وتركيبا بصورة تدريجية. 22 وهذه هي الأساس من وظيفة المواد التعليمية.

وفقاً لكفاءة المتعلمين الذين قد سيطروا على اللغة العربية لأنه من معلمي اللغة العربية، فلذلك المواد التعلمية المقررة على مستوى معلمي اللغة العربية وهو المستوى المتقدم. المواد التعلمية المستخدمة تتكون من كتاب علم اللغة الحديث وعلم الدين الاسلاي .

علم اللغة الحديث Modern Linguistic ذو فرين أساسيين ها: علم اللغة العام أو علم اللغة النظري

• Applied Linguistics General/ Theoretical Linguistics

تعليم اللغة العربية في مدرسة الألسن من ناحية علم اللغة النظري تنتي إلى دراسة علمية وصفية يدرس فيها علم الأصوات، وعلم الفونولوجيا phonology، وعلم الصرف، وعلم النحو، وعلم الدلالة، وعلم اللغة التاريخي، وغير ذلك.

وتعليم اللغة العربية في مدرسة الألسن من ناحية علم اللغة التطبيتي تنتي إلى اكتساب اللغة العربية كاللغة الأجنية التي تشمل دراسة: تعليم اللغة العربية للناطقين بلغات أخري، وعلم أساليب تدريس اللغة العربية، وعلم اختبارات اللغة، وعلم الترجة، و علم النطق ، وعلم اللغة النفي، وغير ذلك.

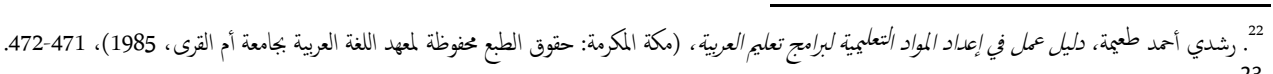

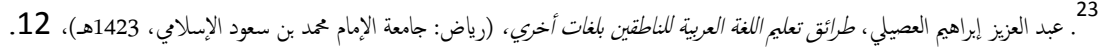


من بعض كنب علم اللغة وهي كتاب اللغة العربية معناها ومبناها تأليف الدكتور تمام حسان، وكتاب التقسيم الهريي للوحدات البنائية للغة العربية تأليف الدكتور إبراهيم بدري، وكناب الكلمة دراسة لغوية معجمية تأليف دكتور حلمي خليل، وكناب اللسانيات وقضابا العربية تأليف مصطفي حركات.

ومن بعض كتب تعليم اللغة العربية هي كتاب تعلم اللغات الحية وتعلمها بين النظرية والتطبيق تأليف الأستاذ الدكتور صلاح عبد المجيد العربي، وكتاب مذكرة في تدريس المفردات للدورات التربوية المكثفة تأليف الأستاذ ممدوح نور الدين، وكناب أساليب تدريس اللغو العربية تأليف دكتور محمد علي الخولي، وكتاب كيف نتعلم لغة ثانية تأليف محمود بن عبد الله المحمود. ومن ناحية علم دين الاسلام وهو علم تفسير القرآن والحديث. ومن بعض كتب تفسير القرآن والحديث المستخدمة وهي كتاب السنة النبوية المطهرة قسم من الوحي الإلهي المنزل تأليف الشيخ محد على الصابوني، وكتاب صفوة التفاسير تأليف الثيخ محد على الصابوني، وكتاب الصابوني في تفسير القرآن المجيد، وكتاب التيان في علوم القرآن تأليف الثيخ محد على الصابوني.

بالنظر إلى الكنب المذكورة أعلاه، يككن استنتاج ذلك أن وظائف المواد التعليمية وفقاً لهذا الأسلوب وهي أولا: ينبغي أن تكون تابعة من حاجات المتعلم وهو علم اللغة الحديث (النظري أو التطبيقي) وعلم الدين، ثانيا: ينبني أن يلتمس رقة قلب المتعلم وهو بدرس تفسير القرآن أو الحديث، لأن المدرس في هذه المرحلة يحتاج إلى الروحانية العميقة.

\section{سادسا: خطوات أسلوب ألسني}

ومن الخطوات التى من أجلها يتم إجراء هذا الأسلوب أولا: يشرح المعلم نصاً باللغة العربية والمتعلمون يستمعون جيداً، ومن الأفضل أن يكون المتعلم في حسن الانتباه ثانيا: يطور المعلم مادة تعليمه حسب حاجة المتعلم، ثالثا: يكنب المعلم المفردات الصعبة أو المفردات الجديدة ليتمكن المتعلم من كتابة تلك المفردات، ثالثا: يكتب المتعلم تلك المفردات على دفترجم، رابعا: يختار المعلم واحدا من المتعلمين ليتكلم عن النص الذي قد سمعه من المعلم، خامسا: يلخص المتعلم ما سمعه من شرح المعلم أمام أصدقائه، سادسا: يستمع المتعلمون الآخرون 
استعداداً لطرح السؤال للمتكلم، سابعا: يناقش المتعلمون فيا بينهم عا حول النص بطريقة السؤال والجواب ، ثامنا: يشجع المعلم طلابه على طرح الأسئلة.

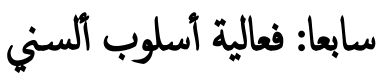

هذا الأسلوب ذو فعالية عظمة في مجال تعليم اللغة العربية، خاصة لمدرسي اللغة العربية، وهي: إن استخدام الأسلوب الألسني، 1) يني قدرة المتعلم على التعبير الدقيق حسب فكرته بدون أي قلق أو خوف أو خجل، و2) يقوي سيطرة المتعلم على أساليب تعليم اللغة العربية الحديثة حسب زمانه، و3) يكون حلا لمشكلات المعلم في المدرسة لأن في هذا الفصل فيه تبادل الأفكار عن علاج صعوبة تعليم اللغة العربية في إندونيسيا، و4) يقوي محارة الكلام لدى المتعلم، وهو بظهور المناقشة الفعالة فيه، 5) يزداد ثراؤها في المفردات المعاصرة حسب تقدم الزمان، و6) يكون المتعلم مسيطرا على مناقشة الأفكار ويري المشكلة من زوايا ختلفة، و7) يستجيب متطلبات الزمان على تعليم اللغة العربية بالطريقة الحديثة، و8) يسد حاجة المتعلم الروحي بوجود الوستمتاع على الجملة الرائعة من القرآن أو الحديث، و9) يضفي إلى سيطرة المتعلم على نظريات تعليم اللغة العببة الفعالة، و10) يتأثر بدقة لكفاية لغوية لدى المتعلم بسبب الأداء اللغوية في حجرة الدراسة، و11) يسحذ قدرة المتعلم في تعلم اللغة العربية بسبب إجتياز خطوات اكتساب اللغة الثلاثة و هي النعرف، والاستعاب، والاستمناع، و12) يقوي كفاءة المعلم في الاتصال بالعربية، أو في فهم النصوص العربية، و13) يحول وبجة نظر المعلم، أن اللغة العربية هي اللغة التي تصلح لكل عصر وليست لغة التخلف كما غُرت من قبل، و14) إثراء معرفة المعلم على الحضارة الإسلامية، لأن جميع كتب التزاث الإسلاي مدوّن باللغة العربية. أحد أهم أسباب الرئيسية في فعالية الأسلوب الألسننى هو المناقشة بين المتعلم في حجرة الدراسة. والمواد التعلمية المستخدمة للمناقشة التى تتكون من علوم اللغة الحديثة، والديانة العربية، وعلوم تعليم اللغة العربية للناطقين بها يحسن قدرة المتعلم على التفكير النقدي و كفائتهم في اللغة العربية لأن تلك المواد التعلمية هي المواد

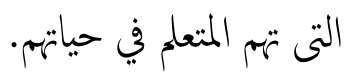


كما قال زاوكيوي و جان جي "من خلال الجمع بين المواضيع والمواد ا المهتمة في الحياة اليومية مع تطوير

المهارات الشاملة مثل الاستحاع، والكلام، والقراءة، والكتابة، وعادات تعلم اللغة من المضاربة، والتحليل، والمناقشة، والتقييم تدريجيا ليتم تطويرها وتدريبها سوف تشجيع النفكير النقدي للمتعلمين."24

إن مدرسى اللغة العربية بحاجة لتجديد وتحديث كفائهم اللغوية. ومدرسة ألسن تكون منتدا لمدرسي

اللغة العربية لتبادل الأفكار والآراء عن تعليم اللغة العربية. إن استخدام أسلوب ألسني في مدرسة ألسن يجعل مدرسي اللغة العربية يناقشون مشاكلهم في التدريس وتقديم الحلول بعضهم البعض. هذا الأسلوب يجعل مدرسي اللغة العربية يتكلمون بالعربية دائما مع الآخربن، إذاكان أحد المدرسين لا يفهم معنى كلمة ما، فإن الآخر سيترجمها باللغة العربية. إن هذه الطريقة فعالة لتقوية كفائهم اللغوية، خاصة في إتقان اللغة العربية المعاصرة.

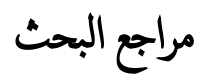

Zahrân, al-Badrâwî Muqaddimah fî 'Ulûm al-Lughah. Assiuț: Dâr al-Fikr, 1993.

Al-Ṭobjî, Ḥussein Ḥamdi. Wasâil al-Ittiṣâl wa al-Tiknûlûjiyâ fî al-Ta'lîm. Al-Kuwait: Dâr al-Qalam, 1982.

Al-Ra'uf al-Sheikh, Fathîi 'Alî Yûnis wa Muhammad 'Abd. Al-Marji' fî Ta'lîm alLughah al-'Arabiyah li al-Ajânib: Min al-Naẓariyah Ilâ al-Tațîq. Al-Qâhiroh: Maktabah Wahbah, 2003.

Ḥarakât, Mușțafâ. Al-Lisâniyât wa Qaḍâyâ al-'Arabiyah. Beirût: al-Mamlakah al'Așriyah, 1998.

Bakr, Ya'qûb. Al-'Arabiyah Lughah 'Alâmiyah. Al-Qâhirah: Jâmi'ah al-Duwal al'Arabiyah, 1996.

Ibrâhîm, 'Abd al-'Alîm. Al-Muwajjah al-Fannî li Mudarrisî al-Lughah al-'Arabiyah. Al-Qâhiroh: Dâr al-Ma'ârif, 1968.

'Ilyân, Ahmmad Fu'âd. Al-Mahârât al-Lughawiyah Mâhiyatuhâ wa Tarâiq Tadrîsuhâ. Al-Riyaḍ: Dâr al-Muslim, 1992.

Muṭâwi', Ibrâhîm Eșmat. Sîkûlûjiyah al-Wasâil al-Ta'lîmiyah wa Wasâil Tadrîs alLughah al-'Arabiyah. Al-Riyaḍ: Dâr al-Ma'ârif, 1983.

24 . Zhaoxi Wei and Gang Ji. Analysis on Informatization Assistance in Deep Learning of College EFL Teaching. Journal of Language Teaching and Research, Volume 9, number 6, November 2018, 219. 
Al-Nâqah, Maḥmûd Kâmil. Ta'lîm al-Lughah al-'Arabiyah li Națiqîn bi Lughâtin Ukhrâ Ususuhu-Madâkhiluhu-Tarâiq Tadrisuhu. Makkah Al-Mukarramah: Jâmiah Ummu al-Qurâ, 1985.

Al-Raḥman, Muhạmmad Nâsir al-Dîn 'Abd. Dalîl Madrasah al-Sun li al-Abhath alAlsuniyah wa Ta'lim al-'Arabiyah bi Indûnîsiyah.

Hassân, Tammâm. Al-Tamhîd fî Iktisâb al-Lughah al-'Arabiyah li Ghairi al-Nâtiqîn Bihâ. Makkah al-Mukarramah: Jâmi'ah Ummul Qurâ Ma'had al-Lughah al'Arabiyah Wahdah al-Buhuth wa al-Manâhij, 1984.

Al-Rukkâb, Jaudât. Tarâiq Tadrîs al-Lughah al-'Arabiyah. Dimashqa: Dâr al-Fikr, 1988.

Husain, Mukhtâr al-Tâhir. Ta'lîm al-Lughah al-'Arabiyah li Ghairi al-Națiqîn bihâ fî Dau'I al-Manâhij al-Hadithah. Al-Haram: al-Dâr al-'Alâmiyah li Nashri wa alTauzi', 2011.

Ṭu'aimah, Rushdî Ahmad. Dalîl 'Amal fî I'dâd al-Mawâd al-Ta'lîmiyah li Barâmij Ta'lîm al-'Arabiyah. Makkah Al-Mukarramah: Ḥuqû al-Ṭab'u Maḥfuẓah li Ma'had al-Lughah al-'Arabiyah bi Jâmi'ah Ummul Qurâ, 1985.

Al-'Așailî, 'Abd al-Azîz Ibrâhîm. Tarâiq Ta'lîm al-Lughah al-'Arabiyah li Nâtịîn bi Lughâtin Ukhrâ. Riyaḍ: Jâmi'ah al-Imâm Muhammad bin Su'ûd al-Islamî, 1423 $\mathrm{H}$.

Sahito, Zafarullah dan Joensuu Finland, Quality in Teacher Education: Evidence from the Universities of Sindh, Pakistan. Journal of Language Teaching and Research, Vol. 9, No. 5, pp. 916-927, Sepetember 2018, 5. 